\title{
Promoting universal financial protection: evidence from the Rashtriya Swasthya Bima Yojana (RSBY) in Gujarat, India
}

Narayanan Devadasan ${ }^{1 *}$, Tanya Seshadri ${ }^{1}$, Mayur Trivedi $^{2}$ and Bart Criel ${ }^{3}$

\begin{abstract}
Background: India's health expenditure is met mostly by households through out-of-pocket (OOP) payments at the time of illness. To protect poor families, the Indian government launched a national health insurance scheme (RSBY). Those below the national poverty line (BPL) are eligible to join the RSBY. The premium is heavily subsidised by the government. The enrolled members receive a card and can avail of free hospitalisation care up to a maximum of US\$ 600 per family per year. The hospitals are reimbursed by the insurance companies. The objective of our study was to analyse the extent to which RSBY contributes to universal health coverage by protecting families from making OOP payments.

Methods: A two-stage stratified sampling technique was used to identify eligible BPL families in Patan district of Gujarat, India. Initially, all 517 villages were listed and 78 were selected randomly. From each of these villages, 40 BPL households were randomly selected and a structured questionnaire was administered. Interviews and discussions were also conducted among key stakeholders.

Results: Our sample contained 2,920 households who had enrolled in the RSBY; most were from the poorer sections of society. The average hospital admission rate for the period 2010-2011 was 40/1,000 enrolled. Women, elderly and those belonging to the lowest caste had a higher hospitalisation rate. Forty four per cent of patients who had enrolled in RSBY and had used the RSBY card still faced OOP payments at the time of hospitalisation. The median OOP payment for the above patients was US\$ 80 (interquartile range, \$16-\$200) and was similar in both government and private hospitals. Patients incurred OOP payments mainly because they were asked to purchase medicines and diagnostics, though the same were included in the benefit package.
\end{abstract}

Conclusions: While the RSBY has managed to include the poor under its umbrella, it has provided only partial financial coverage. Nearly $60 \%$ of insured and admitted patients made OOP payments. We plea for better monitoring of the scheme and speculate that it is possible to enhance effective financial coverage of the RSBY if the nodal agency at state level would strengthen its stewardship and oversight functions.

Keywords: Financial protection, Health insurance, India, National health insurance scheme, Out-of-pocket payments, RSBY, Universal health coverage

\footnotetext{
* Correspondence: deva@iphindia.org

${ }^{1}$ Institute of Public Health, 250, 2nd C Main, Girinagar 1st Phase, Bangalore

560085, India

Full list of author information is available at the end of the article
}

C Biomed Central

(c) 2013 Devadasan et al.; World Health Organization; licensee BioMed Central Ltd. This is an Open Access article in the spirit of the BioMed Central Open Access Charter http://www.biomedcentral.com/info/about/charter/, without any waiver of WHO's privileges and immunities under international law, convention or agreement. This article should not be reproduced for use in association with the promotion of commercial products, services or any legal entity. There should be no suggestion that WHO endorses any specific organisation or products. 


\section{Background}

India spends about $4.3 \%$ of its GDP on healthcare. However, $72 \%$ of this money is paid by individual households through out-of-pocket payments (OOP) at the time of illness, representing one of the highest proportions of OOP in the world [1]; this results in financial barriers to accessing healthcare. Evidence shows that in India about $6 \%$ of patients do not seek care for financial reasons [2]; for those who do seek care, the experience can be catastrophic and impoverishing. Berman et al. estimate that more than 70 million Indians are impoverished every year because of medical expenses [3].

The Rashtriya Swasthya Bima Yojana (RSBY) was launched in April 2008, explicitly to protect the poor from catastrophic hospital expenditure [4]. Under the leadership of the federal Ministry of Labour and Employment, it provides protection for more than 30 million poor households across the country against direct hospital expenses. All poor households in the national below poverty line (BPL) list $^{\mathrm{a}}$ are eligible to enrol in this scheme; details on the scheme's design are provided in Figure 1. RSBY is a voluntary private health insurance scheme, wherein a BPL family of (maximum) five people can enrol with an insurance company by paying a token enrolment fee of US\$ $0.6^{\mathrm{b}}$ per family per year. Insurance companies enrol BPL families and provide them with a RSBY "smart card" that contains the biometric details of the enrolled family; the smart card is necessary for all transactions at the hospital. The premium for each family, which ranges from US\$ 10 to US\$ 12 , is paid by the government directly to the insurance company. An enrolled patient can then seek care for any major ailment that requires admission in empanelled hospitals ${ }^{c}$. Hospitals bill the insurance company based on packages, a basic form of diagnostic related groups (DRG). The insurance company reimburses the hospital up to a maximum of US\$ 600 per family per year. As most of the 1,000 DRG packages are within this upper limit, it is expected that the majority of patients will walk out of the hospital without paying any money at the time of illness. This is expected to improve access to hospital care and protect the family from impoverishment [5]. While the insurance company is responsible for implementing the RSBY; oversight of this scheme is provided by the state nodal agency.

Much has been written about the RSBY, especially regarding enrolment and some key operational issues [6-9]. From initial data, it appears that approximately $55 \%$ of the poor have enrolled in the scheme, ranging from $11 \%$ in the state of Assam to $87 \%$ in the state of Tripura. Low enrolment was due to problems with the BPL list, inadequate information and knowledge dissemination to the population, and technical glitches with the enrolment process itself. The average hospitalisation rate was 26/ 1,000 enrolled, ranging from $0.8 / 1,000$ in Chandigarh to $52 / 1,000$ in Kerala. This hospitalisation rate was above the national average of 20 per 1,000 [2] and indicates that the RSBY may have contributed in improving access to hospital care in some states in India.

However, there are still many gaps in the understanding about the workings of the RSBY, for example, not much is known about the protective effect of RSBY on OOP and impoverishment. Rathi et al. observe that there are OOP expenses by RSBY patients both before and after admission, but do not mention payments during

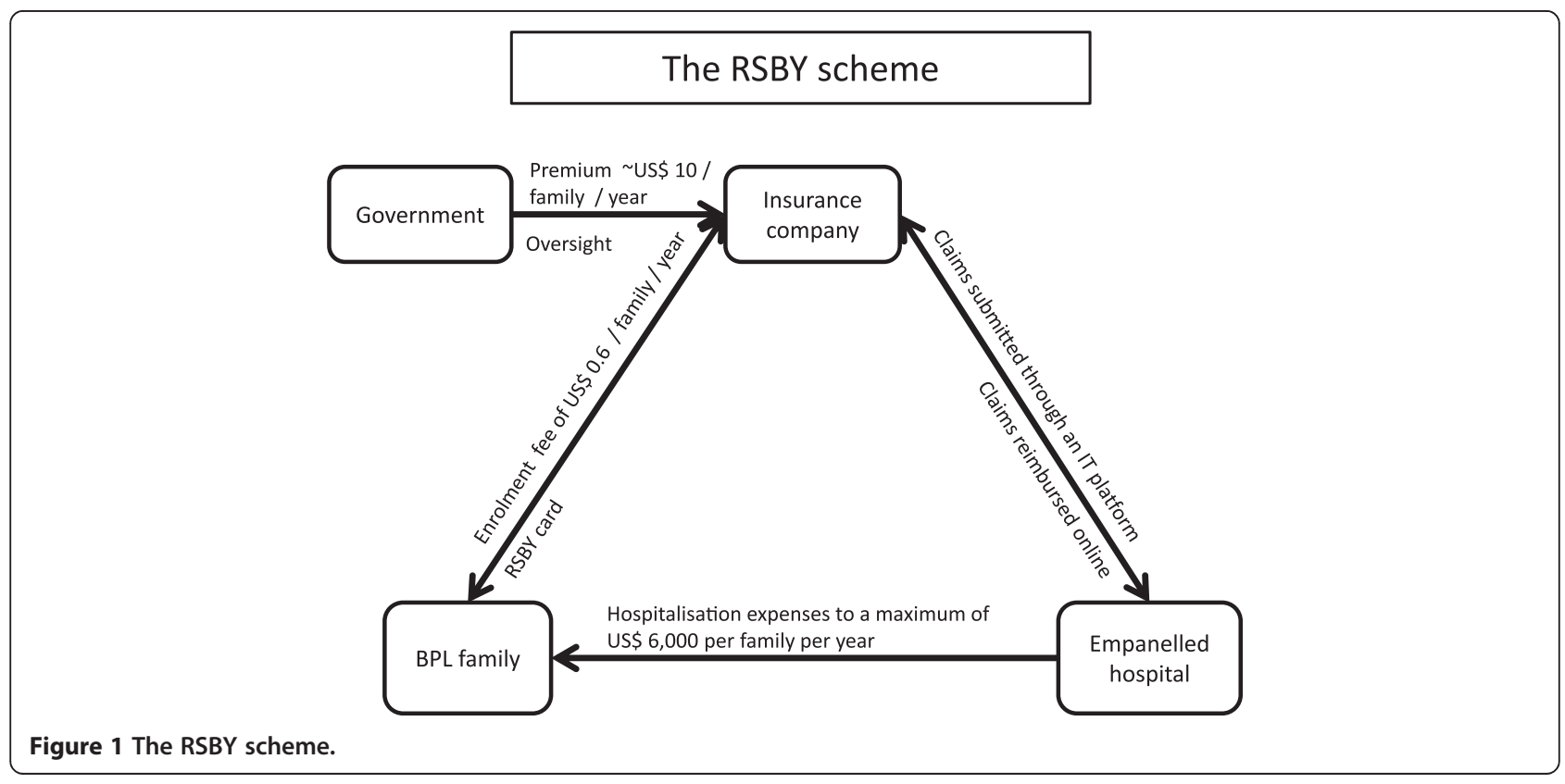


hospital admission [10]. It is in this context that we studied the characteristics of the patients who were hospitalised under the RSBY scheme and the extent to which the scheme protected enrolled families from OOP payments at the time of hospitalisation.

\section{Methods}

This study is part of a larger project measuring the contribution of RSBY in achieving universal health coverage in India. It was conducted in Patan district (Gujarat) in 2011; at the time of the study, only four districts in Gujarat had completed two years of operations under the RSBY. Among these four, Patan was chosen because it had average performance indicators with regards to RSBY, as well as an average human development index (for Gujarat).

A cross-sectional household survey was conducted among BPL households selected on a random, two stage sampling basis. In the first stage, all villages in Patan district $(\mathrm{n}=517)$ were stratified according to the subdistricts. Next, $15 \%$ of all villages in each sub-district were sampled randomly, using probability proportionate to size. Finally, from each of these 78 villages, $40 \mathrm{BPL}$ households were randomly selected. Each of these households was approached, and was administered a standard structured questionnaire enquiring about household details, as well as details about enrolment and utilisation of RSBY benefits during the period 2010-2011. Details of their OOP expenditure both direct and indirect were also recorded. Direct expenses included expenditure on medicines, diagnostics, consultation fees and hospital charges; while indirect expenses included expenses on food, travel and informal fees. Direct expenses could be incurred either before or after the hospitalisation or during the hospital stay. In this article, we have focussed on direct expenses during the hospitalisation episode as this is the expense that RSBY is expected to cover.

Missing households were replaced with the next household in the list until a total of 40 households was reached in each village. If a village did not have $40 \mathrm{BPL}$ households, the adjacent village was included in the cluster and the remaining households were selected from this village. Other than this, in-depth interviews and focus group discussions were held with key stakeholders like community members $(n=14)$, district and state officers $(n=6)$, as well as providers $(n=6)$ till saturation was achieved (providers that saw more RSBY patients were included in the above sample). All interviews were conducted by experienced interviewers in the local language; detailed notes were made and analysed manually. Ethical clearance for this study was obtained both from the WHO ethical review board as well as from the Ethical Committee of the Institute of Public Health (IPH) in Bangalore.

In this document, we present only the findings relevant to utilisation of RSBY benefits, specifically hospitalisation and OOP payments at the time of hospitalisation. All financial data is presented as median with interquartile range.

\section{Results}

Among the 3,120 sampled households, 2,920 BPL families in total had enrolled in the RSBY scheme during the period 2010-2011. The median family size was 5.5 and $48.6 \%$ of the household members were females. There were 16,368 individuals in these families, but the number of individuals enrolled was 13,087 . The median age of the enrolled individuals was 21 years with $36 \%$ of the population being below 15 . The majority of the families $(2,866$ out of 2,920$)$ surveyed were Hindus; $78 \%$ of the families were from a backward caste and 18\% belonged to the lowest caste (SC). Only $1.2 \%$ of the surveyed families belonged to aboriginal groups (ST). There was a relatively even distribution of enrolled families in terms of distance from Patan town. Table 1 provides more details on socio-economic characteristics of the families studied and individuals hospitalised.

Among the enrolled individuals, there was a total of 520 hospitalisation episodes corresponding to an admission rate of 40 admissions per 1,000 enrolled individuals. The common reasons for admission were pregnancy related $(n=96)$ followed by hysterectomies $(n=58)$, injuries $(n=53)$ and cardio-vascular related diseases $(n=51)$. Patients went mostly to private hospitals (73\%), and 93\% of all patients were satisfied with the treatment received. The 520 patients were admitted in 166 distinct hospitals distributed equally between the district and sub-district levels. The majority of hospitals (105) had admitted just one RSBY patient during the period 2010-2011, and only eight hospitals had admitted more than 10 patients. While most patients were admitted in empanelled hospitals, $30 \%$ of the patients were not aware

Table 1 Characteristics of families enrolled and patients benefited by the RSBY scheme in Patan district (2010-2011)

\begin{tabular}{lrr}
\hline Key characteristics & $\begin{array}{r}\text { Enrolled } \\
\text { families }\end{array}$ & $\begin{array}{r}\text { Hospitalised } \\
\text { patients }\end{array}$ \\
\hline Total & 2,920 & 520 \\
Living within 30 km of Patan town (\%) & $1245(43 \%)$ & $254(49 \%)^{*}$ \\
Lowest caste (\%) & $520(18 \%)$ & $118(23 \%)^{*}$ \\
With no land (\%) & $1914(65 \%)$ & $346(67 \%)$ \\
Living in huts (\%) & $1172(40 \%)$ & $192(37 \%)$ \\
With no sanitation (\%) & $2551(87 \%)$ & $436(84 \%)$ \\
$\begin{array}{l}\text { Families dependent on labour as the main } \\
\text { source of income (\%) }\end{array}$ & $2076(72 \%)$ & $382(74 \%)$ \\
Families that consumed <3 meals/day (\%) & $1635(56 \%)$ & $283(54 \%)$ \\
Families that have migrated in the last & $194(7 \%)$ & $54(10 \%)$ \\
year (\%) & & \\
\hline
\end{tabular}

*The difference is statistically significant $(P<0.05)$. 
of the empanelment status of the hospital where they were admitted.

Of the 520 hospitalised, nearly half lived within $30 \mathrm{~km}$ of Patan town. Hospitalisation rates fell steadily with distance (Figure 2), and the admission rates for those who lived more than $30 \mathrm{~km}$ from the town was significantly lower than admission rates for those who lived within $30 \mathrm{~km}\left(\chi^{2}=9.246, P=0.0023\right)$.

There was no difference in admissions between various religious groups, but patients who belonged to SC seem to have a higher admission rate $(42 / 1,000 \mathrm{SC}$ enrolled) compared to other castes $\left(\chi^{2}=11.75, P=0.0006\right)$. The ST population, who is the most vulnerable, had the lowest admission rate of 22/1,000 ST enrolled. More women (57\%) used hospital services than men $(43 \%)$ and this difference was statistically significant $\left(X^{2}=15.429, P=0.000\right)$. Admission rates were higher among adults and elderly compared to children and adolescents. One possible explanation for the low admissions among children was the tendency among parents to use other free government schemes for children and preserve the RSBY benefits for the adults; some informants stated this to be the case during the interviews. There was no difference in admission rates between the different income groups among the enrolled individuals.

Of the 520 admissions, only 13 (3\%) did not have to pay any money for their hospitalisation. The rest incurred a median expense of US\$ 141 ( range, \$48-\$343), either before, during or after admission (Table 2). As the RSBY scheme is expected to protect the patient from direct expenses during hospitalisation, we investigated this in further detail. More than half of the admitted patients had made OOP payments to receive the appropriate care at the time of hospitalisation. This ranged from less than a dollar to more than US\$ 500 in the case of 20 patients (Figure 3 ). The families who made OOP payments tended to live further away and were poorer compared to those who did not make OOP payments (Table 3). Most patients from both groups, i.e., with and

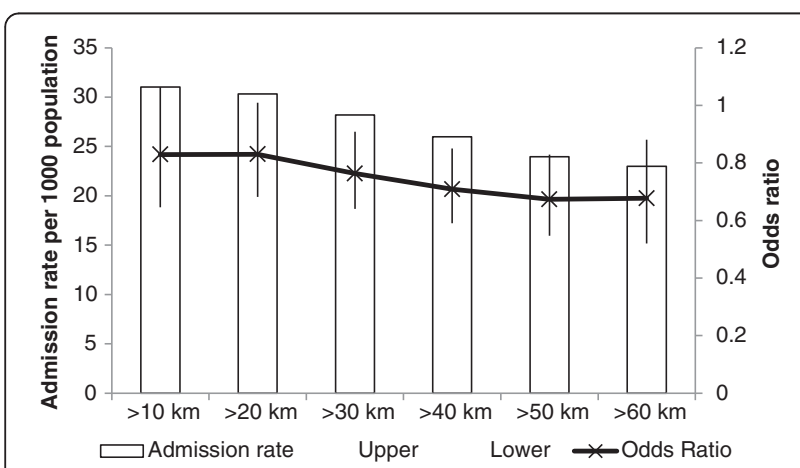

Figure $\mathbf{2}$ Admission rates by distance and the probability of admission by distance groups.
Table 2 Out-of-pocket expenditures among patients enrolled under RSBY in Patan district, 2010-2011

\begin{tabular}{lll}
\hline & $\begin{array}{l}\text { Number of patients who had } \\
\text { to make OOP payments }(\%)\end{array}$ & $\begin{array}{l}\text { Median OOP } \\
\text { expenses (Q1, Q3) }\end{array}$ \\
\hline $\begin{array}{l}\text { Direct expenses } \\
\text { before admission }\end{array}$ & $180(35 \%)$ & US\$ $0(0,40)$ \\
$\begin{array}{l}\text { Direct expenses } \\
\text { during admission }\end{array}$ & $299(58 \%)$ & US\$ $100(46,240)$ \\
$\begin{array}{l}\text { Direct expenses } \\
\text { after discharge }\end{array}$ & $216(42 \%)$ & US\$ $7(0,40)$ \\
Indirect expenses & $489(94 \%)$ & US\$ $18(8,40)$ \\
\hline
\end{tabular}

without OOP, used the private sector and were admitted mainly for delivery and hysterectomy. The median OOP payment in both private and government hospitals was US\$ 100 (range, \$46-\$240).

Despite being enrolled in the RSBY, $58 \%$ of patients (299 out of 520) still made OOP payments at the time of hospitalisation. Our survey indicates that of the $299 \mathrm{pa}-$ tients who incurred OOP, 174 patients had used the RSBY card for hospitalisation. Despite having a RSBY card, the hospitals still collected money from 124 patients at the time of hospitalisation (Figure 4). A possible explanation for this is the alleged 'low' prices of the DRG packages in empaneled hospitals, especially for nonsurgical cases. Doctors admitted that they had stopped seeing RSBY patients with non-surgical conditions as it was 'not remunerative'. Yet another reason mentioned by doctors were the delays and uncertainty of payment by the insurance companies. Hospitals, therefore, tended to ask for advances from patients, make them buy medicines and consumables and sometimes even pay the entire bill, with the promise to return the same when the insurance company reimburses the hospital. Another fifty patients did not receive free care because of problems either with the card $(n=30)$ or with the card reader at the hospital $(n=20)$. Patients mentioned that even a small spelling error on the card or a minor difference in age was reason enough for the hospital to refuse free treatment. Many times patients were asked to supplement the RSBY smart card with additional documents like ration card, BPL card, voter's identity card, etc. Even the insurance companies insisted on documents from the hospitals, such as case sheets, patient identification details, etc. A hospital administrator said "RSBY is a paperless scheme, only on paper."

The doctors justify taking money from patients by citing examples about how insurance companies delay or even refuse reimbursements on flimsy grounds. "Everything matches, the name, the thumbprint, the address, the family details, but the gender may be wrongly entered in the card. That is enough for the insurance company to refuse our claim". As another hospital administrator stated "Insurance companies see only data, not the case sheet." 


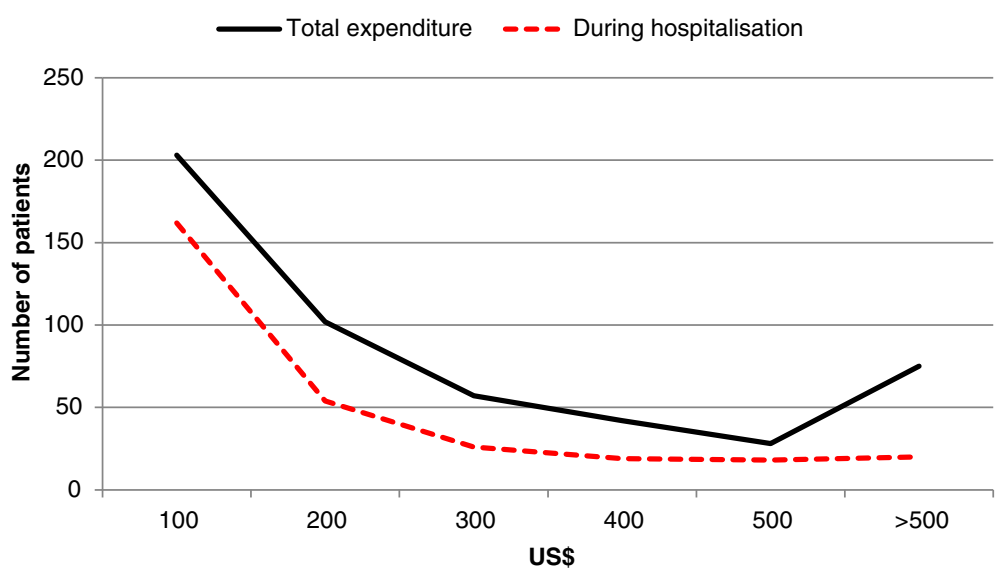

Figure 3 Out-of-pocket expenditure by hospitalised patients in Patan district (2010-2011).

Of the remaining 125 patients who had made OOP payments, 14 had not received the RSBY card even though they had enrolled in the scheme. About 35 patients were admitted to an un-empanelled hospital. Most of the families interviewed stated that they never received any list of empanelled hospitals at the time of enrolment.

Unfortunately, some patients did not use the card because they did not know about it $(n=46)$, or forgot to use it $(n=23)$. Interviews show that while the insurance company launched intensive awareness campaigns, most of the messages were limited to "what" the scheme is and "who" is eligible; there was remarkably little information about "how" to use the card and to benefit from the scheme. Therefore, we had a situation where many patients sought healthcare and made OOP payments, even though they had a RSBY card in their house. They were simply not aware that they could use this card to get free hospitalisation care.

\section{Discussion}

Our study shows that access to hospital care has increased for RSBY enrolees, but patients still continue to make OOP payments even though they were insured. The fact that the admission rate among those enrolled in the RSBY scheme was as high as 40/1,000 enrolled is a positive finding. The National Sample Survey study showed that admission rate was 29/1,000 people in Gujarat and ranged from 18 to 32 per 1,000 population for the poorest in India [2]. It is also gratifying to see that the vulnerable (women, $\mathrm{SC}$ and elderly) have benefited from the scheme. What is worrying, however, is the fact that the most vulnerable population, the aboriginal groups, lag behind in utilisation of benefits. It is also problematic that most of those who received the cards and who benefited from it live close to Patan town. A likely explanation is that the travel cost for those living far away forms a significant barrier to utilising hospital services. The state nodal agency would need to monitor this closely to ensure that those living far from the district headquarters also benefit from the RSBY.

In order to increase the people's financial coverage, the organisers of the scheme need to ensure that patients are protected from making OOP payments. Measures could include increasing awareness about the card and its use, about the rights of RSBY enrolees, and information about

Table 3 Characteristics of patients by out-of-pocket (OOP) payment

\begin{tabular}{lll}
\hline & $\begin{array}{l}\text { Patients who made OOP payments } \\
\text { at the time of admission }\end{array}$ & $\begin{array}{l}\text { Patients who did not make OOP } \\
\text { payments at the time of admission }\end{array}$ \\
\hline Total & 299 & 221 \\
Patients belonging to families that live within $30 \mathrm{~km}$ of Patan town & $130(43 \%)$ & $124(56 \%)^{*}$ \\
Patients belonging to lowest caste (\%) & $64(21 \%)$ & $54(24 \%)$ \\
Patients belonging to landless families (\%) & $203(68 \%)$ & $143(65 \%)$ \\
Patients who live in huts (\%) & $133(44 \%)$ & $59(27 \%)^{*}$ \\
Patients belonging to families where labour is the main source of & $231(77 \%)$ & $151(68 \%)^{*}$ \\
income (\%) & $175(59 \%)$ & $108(49 \%)^{*}$ \\
Patients belonging to families that ate $<3$ meals a day (\%) & $229(77 \%)$ & $158(72 \%)$ \\
Patients that used private hospitals & &
\end{tabular}




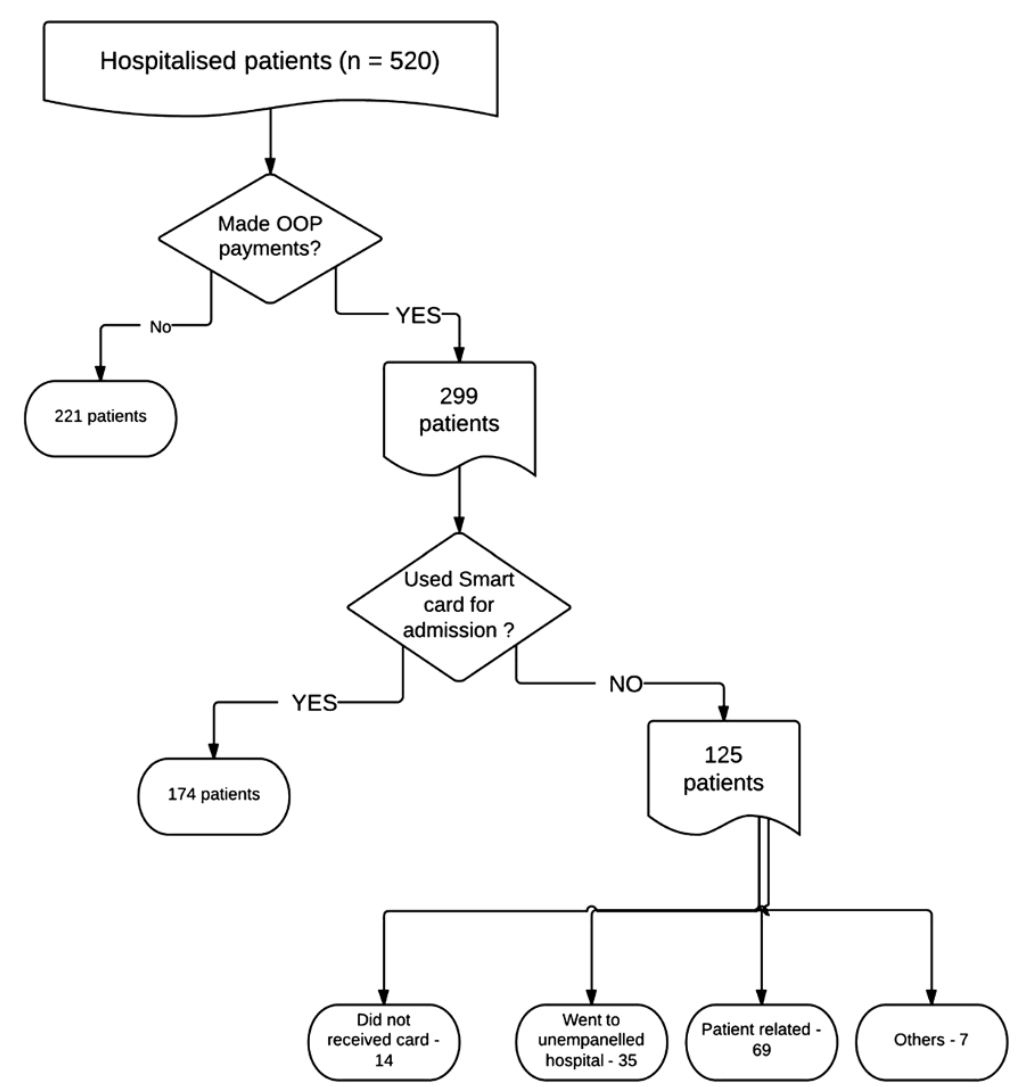

Figure 4 Reasons for patients making out-of-pocket payments at the time of admission.

empanelled hospitals. On the supply side, the organisers need to prevent providers from collecting money from both the patient as well as the insurance company. The fact that nearly $60 \%$ of insured patients had to spend about $10 \%$ of their annual income ${ }^{\mathrm{d}}$ on hospital expenses, despite being enrolled, is problematic. Enrolment in the scheme and utilisation of the RSBY card are merely intermediate steps in a process of having cashless benefits that protects the families from OOP payments. If this objective is not met, then the entire purpose of the scheme is jeopardised. In a 2011 report, Palacios mentions that RSBY patients are being asked to purchase medicines from outside the hospital [5]; our own study clearly shows that OOP payments are a major source of concern and may eventually undermine the credibility of the scheme. Unfortunately, we could not get the insurance companies' views on this important matter, which is an obvious limitation of our study.

In the current design of the scheme, the insurance company is the main implementer of the RSBY scheme. It enrols members, empanels hospitals, processes claims and reimburses hospitals. There is, however, no incentive for them to monitor OOP payments and minimise them. Hospitals that force RSBY patients to buy medicines and pay hospital bills are paid twice: first by the patient, second by the insurance company. Patients are often not in a position to negotiate as they are vulnerable at the time of admission. A major responsibility for the state nodal agency would be to prevent hospitals from charging RSBY patients, which implies close monitoring and taking necessary action when appropriate. Possible suggestions would be to operate a round-the-clock helpline that patients can call or to randomly make calls to patients discharged from hospitals to find out whether they had made OOP payments or to systematically sample patients and find out which hospitals are indulging in this fraudulent activity. It is of course important that hospitals are reimbursed adequately and promptly so that they do not have to ask patients to pay.

Related to this is the fact that 520 patients have sought care in 166 different hospitals. This dilutes the negotiation power of the insurance company with regards to hospitals. While there is a drive to empanel as many hospitals as possible in order to enhance people's geographical access to hospital care, one also needs to balance this with the need to empanel hospitals that provide quality care and that are properly managed. If insurance companies would empanel fewer hospitals that are well distributed geographically across the districts, they could negotiate with these hospitals and purchase a better quality of care for the RSBY enrolees 
[11]. Such forms of strategic purchasing would need to be explored.

Finally, from a universal health coverage perspective, RSBY only targets people estimated to be poor (about $30 \%$ to $40 \%$ of the population). Of these, only $50 \%$ to $60 \%$ are currently enrolled [12], thereby reducing the population coverage even further. When it comes to service coverage, hospitalisations are only a part of the entire health package. Service coverage is also limited because of an upper limit of only US\$ 600 . The main (and unexpected) finding of our study is the poor financial coverage by the RSBY. It was generally thought that even though population and service coverage are still low, financial coverage would be high. Our study, however, shows that more than $40 \%$ of insured patients ${ }^{\mathrm{e}}$ who had used the RSBY card had to pay money at the time of hospitalisation; pre-hospitalisation expenses and indirect expenses would reduce financial coverage even further. While attempts by the RSBY to expand the population and service coverage are laudable [13], it is important and urgent for the RSBY organisers to ensure appropriate financial coverage.

\section{Conclusions}

The RSBY has improved access to hospital care even for the vulnerable population groups. While many patients did not have to pay at all for their hospitalisation, others had to pay for medicines and diagnostics. This issue needs to be addressed urgently if the RSBY is to maintain its credibility and relevance. We recommend that state nodal agencies are strengthened to provide the necessary supervision and regulation of the scheme. These agencies could and should play a more prominent role in ensuring that the enrolment process is inclusive, that benefits actually reach the poor and that there is no abuse of the system. Insurance companies need to be more proactive in strategically purchasing care from hospitals and ensuring that the providers adhere to the contract. Finally, higher awareness among the population about the RSBY scheme and their rights as enrolees needs to be ensured.

\section{Endnotes}

${ }^{a}$ The poverty line is calculated by the Planning Commission based on household consumer expenditure as collected by the National Sample Survey Organisation every five years. Poverty lines are anchored to a calorie intake norm $(2,400$ calories per person per day in rural areas and 2,100 calories per person per day in urban areas). The list of BPL used by the RSBY was calculated in 2002. For further details, kindly refer to the following document. Rath $\mathrm{N}$ : Measurement of Poverty: In retrospect and prospect. Economic and Political Weekly, 2011, 46:40-43.

${ }^{\mathrm{b}}$ Exchange rate used is US\$ $1=$ INR 50.
${ }^{\mathrm{c}}$ Any private or government hospital with more than 10 beds and with an allopathic doctor is eligible to be empaneled. The insurance company is responsible for empanelling the hospitals. All empanelled hospitals are expected to have a smart card reader and a computer that is connected in real-time to the main RSBY server.

${ }^{\mathrm{d}}$ As per the Planning Commission submission, an individual earning less than Rs 781 per month is below the poverty line [Mahapatra D, Sethi N: Spend Rs 32 a day? Government says you can't be poor. Times of India, 2011: Sept 21]. Extrapolating for a family of five, this means that any family earning less than US\$ 937 per annum is below the poverty line. The median OOP of US\$ 100 is roughly $10 \%$ of this annual income.

${ }^{\mathrm{e}}$ Of 520 patients, 125 did not use the RSBY card due to various reasons. Of the remaining 395 insured patients who used the card, $174(44 \%)$ had to make payments at the time of hospitalization.

\section{Abbreviations}

BPL: Below poverty line; DRG: Diagnostic related groups; OOP: Out-of-pocket; RSBY: National health insurance scheme; SC: Scheduled caste; ST: Scheduled tribe.

\section{Competing interests}

ND was recruited by the World Bank to provide technical assistance to the RSBY scheme for the period January 2008 to June 2008.

\section{Authors' contributions}

ND conceptualized and designed the study, and was involved in the acquisition, analysis and interpretation of data. He was involved in drafting the manuscript and revising it. TS was involved in the acquisition, analysis and interpretation of data. She was involved in drafting the manuscript and revising it. MT was involved in the acquisition of data and also in providing critical comments on the draft manuscript. BC was involved in conceptualizing and designing the study and also provided critical comments on the draft manuscript. All authors have given final approval of the version to be published.

\section{Authors' information}

ND is a medical doctor specializing in public health and health financing. He completed his MPH from the Institute of Tropical Medicine, Antwerp, Belgium and his PhD from Gent University, Belgium. After working at various levels from grass roots to $\mathrm{WHO}$, he is currently the Director of the Institute of Public Health, Bangalore, and is the author of many articles in peer-reviewed journals as well as six books on health insurance. TS is a medical doctor with a specialisation in public health. After a stint in a remote corner of India, she is currently a faculty with the Institute of Public Health, Bangalore, and is researching exclusion in RSBY in Karnataka. MT is involved in research activities on different health related issues for around ten years. His prime area of interest has been health financing and insurance, health policy and human development as well as the economics of HIV/AIDS. Over the last four years, he has been involved in teaching and training activities at the Public Health Foundation of India. BC is a medical doctor who has specialised in public health. After an eight-year stint in the Democratic Republic of Congo and an MSc in Community Health at LSHTM, he joined the Public Health Department in the Institute of Tropical Medicine, Antwerp, Belgium. He also has a PhD from the Free University of Brussels. He is the author of many publications on community health insurance.

\section{Acknowledgements}

The authors would like to acknowledge the families and individuals who patiently answered our questions, the contributions of the staff of the Indian Institute of Public Health, Gandhinagar, who were involved in the collection and management of data and the Alliance for Health Policy and Systems Research, WHO, Geneva, for financing the study. Last but not least, we would like to thank all the reviewers, especially Diane McIntyre, Ayako Honda and Bhupinder Kaur Aulakh, who with their insightful comments improved this manuscript. 


\section{Author details}

IInstitute of Public Health, 250, 2nd C Main, Girinagar 1st Phase, Bangalore 560085, India. ${ }^{2}$ Indian Institute of Public Health, Sardar Patel Institute Campus, Drive-in Road, Thaltej, Ahmedabad 380 054, India. ${ }^{3}$ Department of Public Health, Institute of Tropical Medicine, 155, National Straat, Antwerp, Belgium.

Received: 22 February 2013 Accepted: 1 August 2013

Published: 20 August 2013

\section{References}

1. Planning commission: Health chapter: $12^{\text {th }}$ plan. In $12^{\text {th }}$ Five Year Plan. New Delhi: Government of India; 2012:1-71.

2. National sample survey organisation: Morbidity, Health Care and the Condition of the Aged. New Delhi: Government of India; 2006.

3. Berman P, Ahuja R, Bhandari L: The impoverishing effects of healthcare payments in India: new methodology and findings. Econ Polit Weekly 2010, 45:65-71.

4. Devadasan N, Swarup A: Rashtriya Swasthya Bima Yojana: an overview. IRDA J 2008, 6:33-36.

5. Palacios R: A new approach to providing health insurance to the poor in India: The early experiences of Rashtriya Swasthya Bima Yojana. In India's Health Insurance Scheme for the Poor. Edited by Palacios R, Das J, Sun C. New Delhi: Centre for Policy Research; 2011:1-37.

6. Rajasekshar D, Berg E, Ghatak M, Manjula R, Roy S: Implementing health insurance: the rollout of Rashtriya Swasthya Bima Yojana in Karnataka. Econ Polit Weekly 2011, 46:1-26.

7. Jain N: A descriptive analysis of the RSBY data for the first phase. In India's Health Insurance Scheme for the Poor. Edited by Palacios R, Das J, Sun C. New Delhi: Centre for Policy Research; 2011:38-64.

8. Nandi S, Nundy M, Prasad V, Kanungo K, Khan H, Haripriya S, Mishra T, Garg S: The implementation of RSBY in Chhattisgarh, India: a study of the Durg district. Health Culture Soc 2012, 2:1-32.

9. Das J, Leino J: Evaluating the RSBY: lessons from an experimental information campaign. Econ Polit Weekly 2011, 46:85-93.

10. Rathi P, Mukherji A, Sen G: Rashtriya Swasthya Bima Yojana: evaluating utilisation, roll-out and perceptions in Amravati district, Maharashtra. Econ Polit Weekly 2012, 47:57-64.

11. Ranson M, Sinha T, Gandhi F, Jayswal R, Mills A: Helping members of a community-based health insurance scheme access quality inpatient care through development of a preferred provider system in rural Gujarat. Nat Med I India 2006, 19:274-282.

12. The RSBY website. http://www.rsby.gov.in/

13. La Forgia G, Nagpal S: Government Sponsored Health Insurance in India: Are You Covered? Washington, DC: World Bank; 2012

doi:10.1186/1478-4505-11-29

Cite this article as: Devadasan et al:: Promoting universal financial protection: evidence from the Rashtriya Swasthya Bima Yojana (RSBY) in Gujarat, India. Health Research Policy and Systems 2013 11:29.

\section{Submit your next manuscript to BioMed Central and take full advantage of:}

- Convenient online submission

- Thorough peer review

- No space constraints or color figure charges

- Immediate publication on acceptance

- Inclusion in PubMed, CAS, Scopus and Google Scholar

- Research which is freely available for redistribution 